\title{
Mujer, maternidad y familia
}

Woman, Motherhood and Family

Aurora Bernal Martínez de Soria

Universidad de Navarra

abernal@unav.es

\section{Katya Palafox GÓMez}

Universidad de Navarra

kpalafox@alumni.unav.es

Resumen: El objeto del artículo es, a partir de la Antropología de Leonardo Polo, dar respuesta a las cuestiones que surgen desde algunos planteamientos filosóficos y sociológicos sobre la identidad personal y la realización de las mujeres y varones en la familia. Parte de la crisis de la familia responde a una crisis de identidad personal más sobresaliente en el caso de las mujeres. Por esta razón, centramos el estudio en las cuestiones que surgen en el discurso del feminismo en torno a la identidad de la mujer, y en estrecha relación con la consideración de la maternidad y las relaciones familiares.

Palabras clave: Identidad personal, maternidad, mujer, familia.
Abstract: The objective of this paper is to answer the questions that arise from some philosophical and sociological approaches on the personal identity and the realization of women and men in the family. This study is based on the Anthropology of Leonardo Polo. Part of the crisis of the family responds to a crisis of personal identity more outstanding in the case of women. For this reason, we focus the study on the issues that arise in the discourse of feminism around the identity of women and in close relation with the consideration of motherhood and family relationships.

Keywords: Personal Identity, Motherhood, Woman, Family. 


\section{INTRODUCCIÓN}

U na de las aportaciones de Leonardo Polo a la Antropología es la reflexión acerca de una verdad sobre el ser humano que a pesar de ser un conocimiento experiencial obvio, ha pasado desapercibido en las propuestas sobre qué es la persona de numerosos autores. Nos referimos a la argumentación poliana sobre la condición filial del ser humano que sirve también para explicar el ser personal ${ }^{1}$. Polo abre una vía fructífera para comprender filosóficamente la relación que hay entre la condición filial de la persona, la posibilidad y necesidad de la familia -de la maternidad y la paternidad-para el crecimiento humano, y el sentido y finalidad de la educación.

La hipótesis de partida de este breve estudio es que las ideas de Leonardo Polo sobre qué es ser persona, qué es ser hijo, qué es ser padres, qué es ser mujer y qué es ser varón, pueden ayudarnos a esclarecer la confusión y ambigüedad que se produce a partir de algunos planteamientos filosóficos y sociológicos sobre la identidad personal, la realización de las mujeres y varones en la familia, y la conformación de la familia. Los postulados teóricos sobre estos temas alientan proyectos ideológicos que se reflejan en la difusión de estilos de vida desde los que se enfocan modelos de familia, y en la planificación de políticas sociales, familiares y educativas. Buen ejemplo de este proceso es el debate que surge alrededor del desarrollo y aplicación de programas políticos con enfoque de género, dicen sus defensores, o ideología de género, tal y como lo expresan sus opositores². La controversia que no sólo se produce en ámbitos académicos, se alimenta de la formulación de ideas, de problemas y de soluciones de índole predominantemente sociológica ${ }^{3}$. Sin embargo, surgen en esta polémica cuestiones de calado antropológico. Intentamos abordar algunas de ellas en estas páginas para desde un plano teórico delimitar puntos de referencia que sirvan para la educación familiar, para proponer a las mujeres y varones cómo se puede integrar la maternidad y la paternidad con el desarrollo personal y el desarrollo humano.

${ }^{1}$ Cfr. L. POLO, "El hombre como hijo", en J. CRUZ (Ed.), Metafísica de la familia, Eunsa, Pamplona, 1995, 319-327. Para un estudio de este tema cfr. J. F. SELLES, "La filiación personal humana. Estudio acerca de si lo más radical de la Antropología es ser hijo", en Cauriensia, 1 (2006), 201-217.

2 Cfr. A. BERNAL, "Desarrollo, género y familia", en Education Sciences \&Society, 6 (2015), 101-116.

3 Cfr. E. D. WIDMER, O. GONJOUR, "Family Salience Across Nations: Configurations of Morphological Conditions", en V. CESNUITYTÉ, D. LÜCK, E. D. WIDMER (Eds.), Family and Continuity and Change: Contemporary European Perspective, Palgrave Mac Millan, London, 2017, 33-60. 
La temática es importante. En la actualidad es científicamente erróneo y políticamente incorrecto negar el valor de la familia para las personas y para la sociedad, a pesar de que se difunda la idea de que la familia como institución ya no es válida para la sociedad actual. Lo cierto es que la familia está experimentando un proceso de cambio. Desde la década de los 90 del siglo XX, se procede a prestar un nuevo reconocimiento de la maternidad al que se le suma una llamada de atención sobre el valor y la responsabilidad de la paternidad por la aportación de ambos, madres y padres al buen desarrollo de las personas y al desarrollo social. Las políticas sociales dirigidas a mejorar el desarrollo humano se presentan con el objetivo de impulsar el papel de las familias, de los padres y de las madres ${ }^{4}$. $\mathrm{Al}$ mismo tiempo, desde la agenda internacional de política social para promover el desarrollo humano, se intenta proporcionar oportunidades para que tengan cabida en la sociedad, todas las opciones individuales como manifestación de los derechos de las personas; entre estas posibilidades de elección se incluyen, las opciones de cómo concebir la condición sexuada y el modelo de familia. En el marco de promoción del desarrollo social, se pone el acento en impulsar las capacidades de las personas para que elijan y realicen sus vidas ${ }^{5}$. Se plantea que el centro de interés en el desarrollo humano sean las personas, sujetos capaces de elegir cómo vivir. La educación es presentada como uno de los medios imprescindibles para que las personas accedan a oportunidades y las puedan aprovechar.

La crisis de la familia responde, en parte, a una crisis de identidad personal. La crisis de identidad se hace evidente con los cambios que acaecen en la vida de las mujeres, cambios que se sitúan como parte de las causas que han originado la crisis de la familia. Por esta razón centramos el estudio de este artículo en las cuestiones antropológicas que surgen fundamentalmente en el discurso del feminismo, en torno a la identidad de la mujer y que guardan una estrecha relación con la consideración de la maternidad y la familia ${ }^{6}$. Aunque en algunos foros, se produce una reacción de no tener en cuenta los proble-

${ }^{4}$ Cfr. ONU, Asamblea General-Consejo Económico Social, Celebración del $20^{\circ}$ aniversario del Año Internacional de la Familia en 2014. Informe del Secretario General (A/70/61-E/2015/3, 18 de noviembre de 2014), en http://www.un.org [1/VI/2017].

${ }^{5}$ Cfr. M. NUSSBAUM, Creating Capabilities. The Human Development Approach, Harvard University Press, Cambridge, 2011; Las mujeres y el desarrollo humano: el enfoque de las capacidades, Herder, Madrid, 2000.

${ }^{6}$ Cfr. K. L. ALLEN, V. TECH, "Feminist Theory in Family Studies: History, Reflection, and Critique", en Fournal of Family Theory \& Review, 8 (2016), 207-224. 
mas que plantea el discurso feminista, lo cierto es que desde el feminismo se presentan razonamientos sobre los que habría que pensar. Mientras no se proponen soluciones, las ya divulgadas posiciones de algunos feminismos radicales siguen haciendo mella en el modo de enfocar las relaciones entre varón y mujer, y las relaciones familiares. Los problemas en la familia son también problemas sociales como Polo sostuvo hace unas décadas: "Una sociedad que padece la crisis de la familia compromete su futuro"'.

De toda la producción poliana, seleccionamos como fuente de estudio aquellas publicaciones en las que especialmente se considera, relacionados, los temas de la naturaleza y esencia humanas, los tipos humanos, y la familia. En la discusión corriente sobre estos contenidos se argumenta haciendo uso de las nociones de identidad, naturaleza, esencia, libertad, autorrealización, persona y destino humanos desde un mismo plano ontológico. La aportación clave de Polo a la Antropología, es decir, la distinción y comprensión de la dualidad, acto de ser y esencia, así como su estudio sobre la complejidad de la esencia humana, permite, y esto es lo que pretendemos, superar el marco conceptual en el que se sitúa habitualmente el debate agotado y agotador sobre el tema central de este artículo.

\section{Cuestiones antropológicas Desde EL Debate FEMinista SOBRE MUJER Y MATERNIDAD}

Desde la década de los 60 del siglo XX, se impone un enfoque del feminismo categorizado como radical e igualitarista que ha logrado una extensa divulgación. Subrayamos dos de las ideas principales que han calado en el contexto sociocultural contemporáneo:

- La mujer tiene los mismos derechos que el varón (y por tanto debería poder elegir su "destino" en las mismas condiciones y con similares oportunidades que los varones).

- No hay diferencias importantes entre varones y mujeres (las evidentes diferencias biológicas no son relevantes, el dominio técnico de la na-

\footnotetext{
${ }^{7}$ Antropología de la acción directiva, Aedos-Unión Editorial, Madrid, 1997, 12.

8 Se trata principalmente de: La esencia del hombre, Eunsa, Pamplona, 2011; Ética: hacia una versión moderna de los temas clásicos, Aedos-Unión Editorial, Madrid, 1995; Antropología de la acción directiva, Aedos-Unión Editorial, Madrid, 1997; Antropología trascendental, I: La persona bumana, Eunsa, Pamplona, 2003; Ayudar a crecer: cuestiones de filosofía de la Educación, Eunsa, Pamplona, 2006.
} 
turaleza biológica permite controlar las características corporales del ser humano y por tanto disminuir o incluso hacer desaparecer la diversidad entre seres humanos) $)^{9}$.

El discurso feminista apoyado en estas dos ideas simultáneamente mueve a pensar que para afirmar la primera de las sentencias, igual capacidad racional y de elección entre mujeres y varones, hay que aseverar la segunda, no hay diferencias naturales entre ellos ${ }^{10}$. Bajo el abrigo de este tejido de suposiciones de índole antropológica, sociológica y psicológica, se difunde como modelo de vida que para que las mujeres conquisten un puesto de igualdad total ante el varón tienen que renunciar a la maternidad y a hacerse cargo de una familia (al trabajo en el hogar y al cuidado de la familia). Al fin y al cabo, a la mujer se le atribuye tradicionalmente un rol de cuidado ligado a sus características femeninas "naturales" ejemplificadas en la posibilidad de ser madre. El papel social del cuidado es alabado al mismo tiempo que no estimado tanto como otras funciones sociales, las que habitualmente desempeñan los varones.

El feminismo igualitarista lanza a la mujer al mundo profesional -que da prestigio social y poder- como alternativa al mundo doméstico e invita a que estas mujeres profesionales adopten un estilo de vida, a imitación de los varones exitosos, marcado por el Individualismo y el Hedonismo al que ha derivado la cultura moderna. Para la mujer hacerse un sitio en el mundo del varón se convirtió en una lucha contra él, en una lucha de sexos que tornaba irrealizable como proyecto de vida hacer familia.

Para finales de la década de los 80 del siglo XX, se difunden las ideas del feminismo de la diferencia del que destacamos también dos ideas:

- La mujer tiene los mismos derechos que los varones (en este punto se reitera la idea fundamental y compartida por todos los tipos de feminismo).

\footnotetext{
9 Son muy numerosos los estudios acerca del feminismo; citamos como referencia dos estudios que repasan la historia del feminismo subrayando la concepción antropológica, cfr. A. MALO PÉ, Yo y los otros: De la identidad a la relación, Rialp, Madrid, 2016, 26-43; y M. VAAMONDE GAMO, Debate feminista contemporáneo. Aportaciones de John Dewey, Biblioteca Nueva, Madrid, 2015.

10 Simone de Beauvoir es la principal o más influyente autora que fundamenta filosóficamente el igualitarismo y la lucha entre sexos, tal y como lo argumenta en su obra, El segundo sexo (1949). La tesis básica de Beauvoir sobre la mujer es que ésta no nace sino que la hacen, es la Otra, fabricada por el varón de un modo que la hace ser, un ser subordinado y oprimido. El instrumento de dicha subordinación es el cuerpo, la relación sexual y la maternidad. En el feminismo radical confluyen antropologías de inspiración marxista, existencialista, freudiana.
} 
- Hay que comprender las diferencias esenciales entre varones y mujeres.

$\mathrm{Al}$ declarar sendas sentencias se desarrollan dos rutas de reflexión. En una de ellas, se aboga por la diferencia reconociendo el valor igual de ambos sexos. En la otra, se apuesta por dar primacía al valor de la mujer. Desde este feminismo, la maternidad es enaltecida como una opción de vida siempre que sea elegible y no impuesta. Se presenta una maternidad de elección siguiendo dos alternativas: en familia, valorando la relación con el varón-padre o prescindiendo del varón. En la estimación del varón se solicita un cambio, emprender unas relaciones más igualatorias, de respeto recíproco y colaboración para "trabajar ambos en la familia". En la postura de prescindir del varón -porque se considera que la maternidad es una cuestión de realización individual o para evitar sufrir las consecuencias de unas relaciones discriminatorias-, se construye otro sentido de lo que significa la familia. Las opciones a la reproducción artificial posibilitan que la mujer sea dueña de sí y de su capacidad generativa. La Medicina permite sustituir las leyes de la naturaleza, de la biología, que el feminismo observó como una de las causas de la subordinación de la mujer.

La interpretación de qué es ser mujer o ser varón se proyecta en el modo de comprender las relaciones interpersonales entre mujeres y varones, sus roles, sus derechos y su modo de hacer sociedad y familia. En esta disquisición han influido las diversas teorías feministas pero también repercuten otras consideraciones antropológicas, como las que se construyeron para impulsar la Revolución sexual; estas ideas junto a las teorías feministas han cristalizado en la denominada ideología de género y están contribuyendo a cuestionar el contenido de la identidad personal, la identidad sexuada, la maternidad, la paternidad y la familia. Los cambios conducen, no tanto a eliminar a la familia sino más bien a transformar el significado de lo que entendemos por familia, y se invita a experimentar distintas "fórmulas" sobre quienes componen las relaciones familiares y a quienes se atribuyen las funciones y el sentido de la maternidad, de la paternidad y de la filiación ${ }^{11}$.

No pretendemos en este espacio revisar todas las materias antropológicas que se plantean desde los distintos enfoques feministas y los estudios de

${ }^{11}$ Un ejemplo de este planteamiento: A. DOUCET, R. LEE, "Fathering, Feminism(s), Gender, and Sexualities: Connections, Tensions, and New Pathways", en Fournal of Theory Family \& Review, 6 (2014), 355-373. 
género sino únicamente subrayamos aquellas que se relacionan con el tema de ser mujer, ser varón, ser persona y ser familia. Para cumplir con este objetivo, centramos la atención en algunos estudios de Elisabeth Badinter, en los que la autora, al exponer los temas de la maternidad y la mujer en diálogo con el feminismo y con los datos que arroja la sociología, plantea una serie de interrogantes que giran alrededor de nuestro objeto de estudio. Su discurso sirve para plantear las cuestiones básicas que pretendemos resolver desde la Antropología de Leonardo Polo.

\subsection{Problemas en el discurso sobre la maternidad}

En un periodo de cuarenta años, Elisabeth Badinter escribe sobre la maternidad y la mujer ${ }^{12}$. Agrupamos sus reflexiones en torno a tres temas: a) sentido de la maternidad; b) concepciones antropológicas que predominan en la cultura contemporánea; c) relación mujer, varón y familia.

\section{a) Sentido de la maternidad}

Badinter expone que a lo largo de la historia se ha pensado que la maternidad constituye el centro del destino femenino, el principio de sentido y fin de la vida de la mujer. Al hablar de destino se entiende como camino determinado conforme al sexo. La fundamentación antropológica de este destino se razona a partir de la naturaleza femenina apelando al fenómeno o a la realidad del instinto maternal o de un deseo universal de las mujeres de ser madres. Lo natural es asimilado a lo corpóreo y al dinamismo psicológico ligado a los procesos biológicos. A esta presentación de la esencia femenina se opone el feminismo radical negando lo natural de los sexos o reduciendo su importancia.

En el contexto cultural en el que emerge este movimiento y teoría feministas, el modelo de ser humano es del sujeto que se hace a sí mismo y tiene poder de elección sobre la ruta y el tipo de vida en la que se encuentre satisfecho y autorrealizado. Considerar a la maternidad como algo natural y entender lo natural como algo instintivo, determinado por la biología, implica

${ }^{12}$ Cfr. E. BADINTER, ¿Existe el amor maternal?, Paidós, Barcelona, 1980; E. BADINTER, Por mal camino, Alianza Editorial, Madrid, 2003; E. BADINTER, La mujer y la madre, La esfera de los libros, Madrid, 2011. 
situar a la mujer en una posición inferior a la del varón. El ideal de ser humano que se enaltece en la Modernidad es el del que actúa libremente respondiendo con su libre elección. Lo corporal, lo natural tiene menos importancia y está al uso y libre arbitrio de las personas. Por tanto, la maternidad pierde valor para las mujeres que quieren realizarse como personas, como sujeto de derechos: "Al no ser ya la maternidad el único modo de afirmación personal de una mujer, el deseo de tener hijos, puede entrar en conflicto con otros imperativos"13.

No obstante, con la posibilidad de regular la natalidad y con ello, de elegir la maternidad, el feminismo de la diferencia admite la maternidad como un camino vital elegible para las mujeres. Badinter explica que al darse la oportunidad de una maternidad elegida, buscada, se vuelve a situar el ser madre en la definición de lo femenino volviendo a cierto Naturalismo. Se justifica la elección de la maternidad como respuesta al deseo universal de la mujer de ser madre. La referencia a la naturaleza ha cambiado, se continúa viendo únicamente en una dimensión biológica-psicológica pero sin una relación con ella de respeto, por el contrario es de dominio mediante la técnica médica. El sentido que se reconoce a la maternidad no es sólo tener hijos como realización personal sino que esta autorrealización se culmina cuando se logra una crianza y educación con éxito. Las madres que eligen serlo intentan que nada falle en la vida de sus hijos: salud, bienestar, capacidad y posibilidad de elección en la vida. La maternidad se adopta como una tarea profesional, y al hijo se le concibe como el resultado de una proyección individual. Y aunque los padres se ven en la misma tesitura, suelen ser las madres las que cargan con más responsabilidad y doble trabajo aunque se intenta un reparto de tareas y un reparto en el desempeño de los mismos roles.

La maternidad tiene sentido porque es elegible y lo es por sentimiento, por deseo, por cálculo, por presión social. La mujer tiene que conciliar diversos intereses. El resultado en aquellas sociedades desarrolladas en las que hay

13 E. BADINTER, La mujer, op. cit., 23. La siguiente consideración de la autora describe la asimetría entre los sexos respecto a la maternidad y la paternidad, E. BADINTER, Por mal camino, op. cit., 163: "De entrada, ella está sujeta a su cuerpo, mientras él está liberado de él. La maternidad es su destino, mientras que la paternidad es una elección. Esta cosmogonía sexual plantea más cuestiones de las que resuelve. Considerando a la maternidad la esencia de la feminidad, se da a entender que quien la rehúsa es una anormal o una enferma. Al tildarla de 'viril', se le despoja de su identidad y se le declara indigno de su sexo". 
posibilidad de elección es que nos encontramos con madres de numerosos hijos, madres que concilian tener hijos y el trabajo profesional, mujeres que renuncian a tener hijos o tienen pocos hijos por una realización profesional o mujeres que tienen hijos a cualquier precio $^{14}$. Aunque se ha revitalizado que la maternidad sea un aspecto importante de la identidad femenina no representa un hecho necesario para que la mujer experimente la plenitud y sentido de su vida ${ }^{15}$.

\section{b) Cultura contemporánea}

Badinter advierte que sobre las elecciones de las mujeres repercuten los valores que predominan en las sociedades y que materializan el Individualismo, Hedonismo, Naturalismo y Culturalismo. El Individualismo conduce a situar en un lugar central al dilema de qué interés es el que en la vida hay que priorizar. Las mujeres dudan, observan la dificultad para compaginar la realización de sí mismas y la maternidad, con más razón si se proyecta una vida de bienestar o de éxito en el ámbito profesional; ser madre, dedicarse a la familia conlleva mucho sacrificio ${ }^{16}$. Pero también sucede que las mujeres opten por tener hijos como un contenido de su propia realización. Esta visión tiene diversas consecuencias en los modos de vida y de hacer familia que se adoptan. Uno de ellos es pensar en ser madre sin importar la figura del padre. Otro es ver a los hijos como individuos a los que hay que garantizar sus derechos y su vida de bienestar. En este caso, se admira socialmente que las madres de tales hijos gozan de gran capacidad de altruismo ${ }^{17}$.

El Naturalismo de la Edad Moderna se reaviva en la década de los 70 del siglo $\mathrm{XX}$, y se divulga y extiende en los 90 . Lo novedoso en esta última etapa es razonar la realidad natural de la maternidad con datos de las ciencias de la salud. Los estudios científicos muestran la importancia de la ligazón entre madre y sus hijos, delimitando un tipo de crianza y educación con resultados positivos o negativos en la salud física, salud mental, salud social y bienestar. Este

${ }^{14}$ Ibidem, 26.

${ }^{15}$ Ibidem, 190.

${ }^{16}$ L. R. ENNIS (Ed.), Intensive Mothering: The Cultural contradictions of Modern Motherhood, Demeter Press, Bradford, Ontario, 2011.

${ }^{17}$ E. BADINTER. La mujer, op. cit., 24: "Del don de la vida de otros tiempos, se ha pasado a una deuda infinita con respecto a aquel que ya no nos impone ni Dios ni la naturaleza, y que un día sabrá recordaros que él nos pidió nacer”. 
Naturalismo se resuelve como una opción cultural ${ }^{18}$. Se hace y se divulga una cultura de la maternidad natural-científica ${ }^{19}$.

El Culturalismo también está presente a la hora de construir el sentido de la maternidad. Partiendo de las tesis de Simone de Behavoir, por contraste con el Naturalismo, se dice que hablar de la esencia de la mujer o de la naturaleza femenina es una construcción cultural. Pero en la actualidad, admitiendo que así es, se adopta culturalmente el Naturalismo de dos modos, respetando una naturaleza natural -la originaria-, transformándola mediante la técnica médica -buen ejemplo de ello es el recurso a la reproducción asistida-. Aunque esta segunda vía parezca anti natural, en realidad asume una tesis naturalista y es que la maternidad es una realidad humana básicamente ligada a la biología, idea que es un producto cultural.

\section{c) Relaciones familiares}

La identificación de lo femenino con unos roles sociales distintos de los roles que caracterizan a la masculinidad ha pasado, en numerosas sociedades, a ser un fenómeno del pasado. De aquel planteamiento, vigente durante muchos siglos y en diversas sociedades y culturas, de configurarse roles complementarios se ha pasado a adoptar roles intercambiables. La transición de una delimitada experiencia social de la feminidad y la masculinidad a otra alternativa está ocasionando una crisis de identidad que afecta a la dinámica de las relaciones entre mujeres y varones en todos los ámbitos sociales, y ésta repercuten en las relaciones intergeneracionales, relaciones que se aprecian de manera intensa en la familia ${ }^{20}$. Estamos experimentando una redefinición de las relaciones hombres-mujeres y de sus libertades recíprocas.

${ }^{18}$ Cfr. L. SMYTH, "The Creativity of Mothering: Intensity, Anxiety, and Normative Accountability”, en V. CESNUITYTÉ, D. LÜCK, E. D. WIDMER, Family and Continuity and Change, op. cit., 269-290.

19 Se retorna a presentar la maternidad como una vocación elegida pero con las características del instinto maternal, para la que la guía es la ciencia: "El hijo es la obra de una vida porque es una creación apasionante con la que ninguna otra puede rivalizar. Velar por él desde su nacimiento, ayudarle a desarrollarse en cada etapa, para lograr la felicidad y el orgullo de ver un día a un adulto realizado no es una ambición mediocre", E. BADINTER, La mujer, op. cit., 148.

${ }^{20}$ Pierpaolo Donati, también desde la perspectiva de la sociología, reitera estas ideas de Badinter. Este autor considera que la redefinición de lo masculino y lo femenino, en al que prima la elección del individuo, tiene consecuencias en la vida familiar porque la familia es el lugar generativo y regenerativo fundamental de la diferencia sexual. El tema, explica Donati, es más profundo que la reasignación de desempeño de roles. Cfr. P. DONATI, La familia como raíz de la sociabilidad, BAC, Madrid, 2013. 
No se quiere construir la identidad de varones y mujeres siguiendo unas pautas sociales según una normatividad que procede de la asignación de unos roles sociales específicos por sexo. Las personas redefinen la masculinidad y la feminidad pero sin llegar, ni en la teoría ni en la vida práctica, a configuraciones concretas. Badinter constata el punto de atasco en el que nos encontramos respecto al intento de definir los géneros a partir de los datos que arrojan los estudios sociológicos. Critica que para solucionar la cuestión de la identidad sean válidas las generalizaciones que se construyen socialmente de qué y cómo son mujeres y varones. Los varones se rebelan cada vez más ante las generalizaciones que hacen de ellos las mujeres y viceversa ${ }^{21}$. La mayoría de las mujeres y varones quieren vivir en familia armónicamente y los planteamientos del feminismo radical o del feminismo de la diferencia (en el que la mujer se sitúa como ser humano superior al varón) no corroboran el sentir y pensar de una gran mayoría de la población.

Es difícil, sin caer en contradicción, distinguir a hombres y mujeres como dos entidades con intereses completamente diferentes y abogar por la indiferenciación de los roles como la única vía para la igualdad de $\operatorname{sexos}^{22}$. Similar irrealidad se reproduce tanto en las teorías que describen una psicología masculina y otra femenina, impermeables una a otra, o dos identidades sexuales fijas y estáticas como en las que se empeñan en que sólo existe un sexo único. En la opinión de Badinter, los roles indiferenciados no tienen por qué ser identidades indiferenciadas, la diferencia de sexos es un hecho que no predetermina los roles y las funciones ${ }^{23}$.

En este discurso surgen directa o indirectamente algunas cuestiones antropológicas básicas como son:

- ¿La naturaleza marca un destino específico a la mujer? ¿Es la maternidad algo instintivo?

- ¿Se puede definir la naturaleza femenina o la esencia de la feminidad?

- ¿Qué relación hay entre naturaleza, cultura, libertad e identidad personal?

${ }^{21}$ E. BADINTER, Por mal camino, op. cit., 154: "La mujer prisionera de su naturaleza, los hombres obligados a cambiar de cultura. Mensaje contradictorio donde los haya, que desorienta a unos y exaspera a otras".

22 Ibidem, 49-50: "Ahí reside el problema teórico del nuevo feminismo. ¿Cómo redefinir la naturaleza femenina sin volver a caer en los viejos clichés? ¿Cómo hablar de 'naturaleza' sin poner en peligro la libertad? ¿Cómo sostener el dualismo de los sexos sin reconstruir la prisión de los géneros?”.

23 Ibidem, 179. 
- ¿Se construye la identidad de las personas por el desempeño de unos roles o funciones?

- ¿El planteamiento moderno de autorrealización libre e individual como medio de construir la identidad coincide con el proyecto de crecimiento personal?

Para responder a estas cuestiones, interrogantes relacionados entre sí, habría que entender: qué es ser persona, qué es la naturaleza humana, en qué consiste la libertad y la realización personal, la relación entre naturaleza y cultura, así como entre persona y cultura, qué es ser mujer, qué es ser varón, en qué radica la igualdad y la diferencia entre mujeres y varones, qué es ser madre, y qué es ser padre, qué es la maternidad y qué es la paternidad. No esperamos encontrar soluciones desarrolladas de estas cuestiones en la Antropología que Polo, sin embargo, pretendemos, con la aclaración de los conceptos básicos acerca del ser humano, situarnos en la pista que nos encamine a la resolución de algunos de los cuestionamientos esbozados.

\section{NATURALEZA Y PERSONA}

Desde la comprensión de las nociones básicas antropológicas como son la de naturaleza humana y persona se puede resolver si es razonable delimitar instintos en el ser humano, determinaciones biológicas, destinos naturales, autorrealizaciones absolutas, identidades constituidas ex novo. A partir de este conocimiento del ser humano buscamos resolver las cuestiones relacionadas con la mujer y que inevitablemente suscitan solucionarlas en correspondencia con el varón.

\subsection{Naturaleza, esencia y persona}

La primera idea poliana que cabe destacar es que con la noción de naturaleza no se explica de un modo completo qué es el ser humano: "El hombre es sustancia, naturaleza y además esencia" ${ }^{24}$. Con el concepto de esencia se abarca a las nociones de sustancia y naturaleza ${ }^{25}$. Mediante el término sus-

${ }^{24}$ Cfr. L. POLO, La esencia del hombre, op. cit., 97.

25 Cfr. ibidem, 221: "sustancia no es lo mismo que naturaleza, porque la naturaleza añade algo a la sustancia, que justamente es el principio de operaciones". Sólo las sustancias superiores, por ejemplo, los animales, son naturaleza según el pensamiento poliano. 
tancia, Polo hace referencia a la composición del ser humano, a la unión sustancial entre el cuerpo y el alma. El ser humano por su dimensión corporal, por ser un ser vivo corpóreo, es y está instalado en el mundo, relacionado con el cosmos - con la unidad de orden que constituye el mundo-. Pero no es un ser más del cosmos. El cuerpo humano es concasual con el alma humana directamente creada por Dios, y no viene del cosmos, ni se desarrolla desde el cosmos. El ser humano no es una realidad intracósmica porque tiene alma que no procede del cosmos, y está dotado de una perfección distinta y superior a la perfección del cosmos que viene dada por la causa final ${ }^{26}$.

La noción de naturaleza añade a la de sustancia captar como un ser es principio de operaciones. Y la reflexión sobre las operaciones propias del ser humano, las operaciones racionales, tal y como se manifiestas en los actos libres, abre el camino para comprender el concepto de esencia humana: "La esencia del hombre está vinculada con la naturaleza del hombre de una manera distinta de como está el universo como esencia respecto de las naturalezas intracósmicas [...] la esencia del hombre es sencillamente la capacidad que tiene de autoperfección" ${ }^{27}$. Polo también denomina a este proceso de perfección, autoesencialización ${ }^{28}$.

Las naturalezas intracósmicas están determinadas por una causa final, una unidad de orden que es su perfección. Sin embargo, el ser humano se dota a sí mismo de su esencia a partir de su naturaleza -a partir de lo que es-, es decir, se autoperfecciona y así se conduce a su fin. La perfección se "materializa" en hábitos o dicho de otro modo, la esencia como perfección es hábito. Los hábitos tienen que ver con la finalización de la naturaleza. También el ser humano puede "autoestropearse". La autoperfección no está determinada por la naturaleza sino que sigue la libertad, y la consideración de la libertad remite a la realidad del ser personal.

“(...) si una naturaleza es susceptible de perfección, y por lo tanto de esencialización, eso requiere una libertad. Pero eso ya no es esencial, sino supraesencial; eso requiere una libertad y, por tanto, persona ante todo significa libertad, es un acto de ser en y como libertad"29.

${ }^{26}$ Ibidem, 96.

${ }^{27}$ Ibidem, 98.

${ }^{28}$ Ibidem, 99.

${ }^{29}$ Ibidem, 99. 
Polo aclara cómo entendemos habitualmente la libertad relacionada con la naturaleza humana, con la voluntad. El ser humano elige medios para alcanzar un fin, la felicidad, pero no elige querer ser feliz, lo quiere por naturaleza, aspira a ello, únicamente elige cómo serlo. Sin embargo, la libertad del ser humano radica principalmente en el ser personal. El acto de ser humano se caracteriza por la libertad, aunque no sólo por la mera libertad ${ }^{30}$. Y por ello, "lo verdaderamente humano es la persona, el acto de ser humano. Por eso suelo distinguir entre acto de ser humano y esencia del hombre" ${ }^{{ }^{31}}$.

Desde esta perspectiva antropológica y en la comprensión de los conceptos de naturaleza, esencia y persona referidos al ser humano, destacamos las ideas fundamentales que podrán servir para solventar algunas de las cuestiones que motivan este estudio. La naturaleza humana difiere radicalmente del natural de los otros seres del mundo que conocemos, y tal distancia en el orden del modo de ser también se observa respecto a los seres vivos superiores, los animales. La manifestación más evidente de esta diferencia es el orden de la vida, "impuesto" por el cosmos en el caso de los animales, autodado, libre, en el caso de los seres humanos. No está justificado utilizar el fenómeno del instinto para explicar el comportamiento humano. Y por esta razón no es apropiado desde una perspectiva antropológica insistir en un instinto para explicar la maternidad, en un deseo natural, entendiendo por naturaleza la dimensión biológica del ser humano. El comportamiento humano no está determinado por la naturaleza que no está finalizada por el orden del mundo, por las leyes biológicas. El sentido de la vida humana no está fundamentado en el orden de la vida en el mundo, lo trasciende. Y por ello, no es lógico describir un destino humano determinado por la naturaleza, únicamente podría reconocerse un destino si la naturaleza humana estuviera compuesta de un cuerpo y un alma que proceden del mundo. Argumentar que el ser humano tiene instintos que dan sentido a su comportamiento esconde un error cuya causa es un reduccionismo en el conocimiento de la naturaleza humana.

En el otro extremo de este reduccionismo se sitúa la consideración de una libertad absoluta fundamentada en la naturaleza humana, idea de la que se deduce que el ser humano se hace a sí mismo de la nada, de la "casi nada" por-

${ }^{30}$ Ibidem, 105. Con otras palabras, ibidem, 101: "Se trata de un emerger de la esencia a partir de la naturaleza; es un emerger de la naturaleza como superior a ella, y eso sólo puede explicarse por el acto de ser, es decir, porque su acto de ser es personal es por lo que la naturaleza se autoesencializa".

31 Ibidem, 101. 
que es ya algo, un ser libre, con capacidad de actuar libremente -libertad entendida como libre elección-. Sin embargo, el ser humano no es sólo libertad, ni como naturaleza ni como persona. La autoperfección es perfección de una naturaleza recibida y aceptada por la persona. Necesitamos completar el saber de este tema ahondando en las nociones de especie y de persona.

El término especie está elaborado desde la biología y se define propiamente como un modo de ser capaz de generar. Polo sostiene que el ser humano no es sólo un individuo de una especie, es más, indica que ni siquiera los seres vivos son individuos de sus respectivas especies: "En rigor el llamado individuo viviente no es propiamente individuo. Precisamente porque está finalizado por la especie, no acaba de ser un individuo, o sea, no agota su especie, es decir, no la realiza enteramente, sino que está finalizado por ella" ${ }^{32}$. La finalidad de las especies viene determinada por la finalidad del cosmos, la causa final, la unidad de orden, la esencia del cosmos. Una de las finalidades es perpetuarse. La generación es una de las finalidades de las especies, por ello para el animal la generación es central. Pero la finalidad del ser humano no se subordina a la finalidad de su especie ${ }^{33}$.

Luego que el ser humano no sea individuo de su especie no se explica por razón de que esté finalizado por ella, no lo está, la especie humana está en el orden de la esencia humana. El ser humano tampoco agota su especie aunque su esencia es superior a su especie, va más allá de ella. Así que el ser humano es más que un individuo de una especie porque es individuo en el sentido pleno, es decir irreductiblemente. Cada ser humano es cada quien, de este modo la noción de individuo se cumple enteramente ${ }^{34}$. La generación es central también para el hombre, puesto que como no está finalizado por la especie, tiene que propagar la especie y lo hace, como todo lo que hace, libremente.

Con el concepto de especie comprendemos la naturaleza resaltando la capacidad de esta segunda de propagar la vida. La generación en la especie humana se produce mediando la libertad, y alcanza más valor que en el resto de las especies. Desde esta perspectiva, la maternidad y la paternidad suponen una elección de valor de las personas humanas pero no en razón de una operación que se actualiza por la especie sino en razón de la persona por la que se

32 Ibidem, 106.

${ }^{33}$ L. POLO, Ética, op. cit., 52: "La biología puede explicar el surgimiento de especies nuevas; la humanización no se puede explicar así, porque la inteligencia trasciende la especie".

${ }^{34}$ La esencia del hombre, 107. 
esencializa, se perfecciona, se finaliza la naturaleza. La maternidad y la paternidad pueden constituir un modo de autoperfección de la persona manifestativa de su irrepetibilidad. Se es madre por un padre y de un hijo, se es padre por una madre y de un hijo, se es hijo de una madre y de un padre.

Dentro de la especie humana cada hombre es un tipo, es decir, cada ser humano no realiza su especie de igual modo que lo hace otro individuo. El hombre desde el punto de vista de su especie no es igual a otros, sino que es tipo. Cada hombre es típico ${ }^{35}$. La alusión a los tipos merece por nuestro objeto de estudio una atención aparte. Pero antes completamos desde la Antropología de Polo la respuesta a qué es el ser humano. Hasta ahora se ha expuesto que el ser humano no sólo es sustancia, ni sólo naturaleza, sino que hace falta comprender la esencia del hombre. Falta añadir que no es suficiente con considerar la esencia para explicar al ser humano, el ser humano es persona, y lo es por el acto de $\operatorname{ser}^{36}$. Desde el conocimiento del ser personal se puede comprender en qué se fundamentar el valor, la excelencia en el ser, la dignidad hu$\operatorname{mana}^{37}$.

“¿Cómo describiríamos la esencia en cuanto distinta del acto de ser? Esa distinción la encontré en los años 50, seguramente en los años 55 y 56 y yo la llamo así: lo que depende del acto de ser personal así entendido hay que llamarlo disponer. Por eso la esencia humana es el disponer. Éste se puede describir como habitualidad, como relación entre los tipos y los bábitos, puesto que, como hemos dicho, los hábitos se asientan sobre la naturaleza y la naturaleza es típica, no es ni fin, ni tampoco es agotada" ${ }^{\text {. }}$.

Dicho de otro modo, la persona es, y forzamos el sentido, "haciendo" el disponer. No se trata de un hacer con el significado literal de producir, sino de un ser, existir, dinámico que sitúa en acto la potencialidad de la esencia -disponer-. Polo aclara los dos sentidos del disponer de la persona en la esencia

35 Ibidem, 107-108.

${ }^{36}$ La exposición sistemática de este concepto se encuentra argumentada en Antropología trascendental, I.

${ }^{37}$ La esencia del hombre, op. cit., 218: "El hombre no es su esencia, sino que la esencia es suya. En cambio, el ser humano no es del hombre, sino que el hombre es ese ser. Ya he dicho que yo suelo emplear estas fórmulas: acto de ser humano y esencia del hombre. En el hombre me parece que hay que distinguir realmente el ser y la esencia; y que la gran fecundidad de ese hallazgo tomista culmina, es más tajante, y se ve por otra parte con mayor claridad, justamente en antropología".

${ }^{38}$ Ibidem, 128. 
humana ya que se trata de una noción dual: tener en el propio poder y distribuir adecuadamente ${ }^{39}$. Se tiene en el propio poder lo disponible, se dispone de lo disponible, en función de lo disponible, y por tanto disponer, en este sentido, es la capacidad de tener; la esencia humana es la capacidad de tener. Es un disponer que sigue distintos modos, según la capacidad, según lo disponible. El ser humano puede disponer con la voluntad y con el cuerpo, y dispone de lo que conoce. La persona es, y es libre se proyecta en la esencia como disponer. "Disponer es la esencia vista desde la libertad de la persona, porque la persona es libre, su esencia es disponer. (...) en el caso del hombre siendo su acto de ser libertad su esencia es disponer"*0.

La igualdad más radical se asienta en el ser personal. Todos los seres humanos son igualmente personas. La afirmación de la igualdad es compatible con la realidad de la diversidad o diferencia entre personas. La diferencia se debe básicamente a dos condiciones: las características básicas de parte de lo disponible, las dadas (especie, naturaleza, sustancia individual) y las que derivan de la esencialización (la adquisición de hábitos, de disposiciones, del tener, de la libertad). Para el desarrollo humano, es importante admirar la dignidad de la persona por ser quien es y por cómo es su disponer. Sólo desde estas condiciones sociales de reconocimiento del valor de cada persona y de su esencia (tipificada) y de dejar libertad en la esencialización, se puede comprender la igualdad y la diferencia entre los seres humanos en la vida práctica.

Para extender estas ideas al tema de la igualdad y diferencia entre mujeres y varones precisamos entender la noción de tipos. Antes de abordar el contenido de lo que expone Polo sobre la categoría de tipos humanos retomamos y completamos una idea expuesta al explicar qué es la esencia humana. La autoperfección de la persona no es un proceso de construcción de la nada sino que consiste en finalizar la naturaleza. La autoperfección es un proceso de disponer por el ser personal. El disponer remite a lo disponible, luego el ser humano dispone según su esencia (que es disponer) pero no dispone de la esencia. Esta consideración conduce a orientar la libertad y a apreciar el tipo que cada ser humano es, lo que le impulsa a crecer en positivo, a una autorrealización que parte de lo que se es. El ser humano no se da a si mismo el ser, ni la

\footnotetext{
${ }^{39}$ Ibidem, 129. Muchos autores han profundizado en este tema, por ejemplo J. URABAYEN, "La esencia humana como disponer indisponible”, en Anuario Filosófico, 29 (1996), 1051-1060.

${ }^{40}$ Ibidem, 129.
} 
vida, ni los elementos básicos de cómo es ${ }^{41}$. Por esta razón es crucial considerar los tipos humanos. Desde la perspectiva de Polo, no es apropiado hablar de identidad como noción que exprese qué es el ser humano ${ }^{42}$. En el ser humano entendemos dualidades, entendemos quien es por la dualidad acto de ser esencia. Sin embargo, en algunos textos Polo utiliza la expresión identidad personal con un significado de referencia a cada persona, como es el uso en el lenguaje corriente ${ }^{43}$.

\section{Tipos humanos}

De la mano de Polo distinguimos en cada ser humano lo biológico, lo típico, su esencia y el ser persona. El estudio de los tipos, de la noción de tipo realizado por Polo clarifica cómo se trabaja las clasificaciones de los seres humanos en grupos ${ }^{44}$. Además de explicar la necesidad de desvelar las tipologías en el estudio antropológico, Polo aclara cual es la utilidad de las tipologías, y también su limitación, en la investigación sociológica ${ }^{45}$. En el discurso sobre mujer y varón, sobre feminidad y masculinidad se parte de la base de una investigación sociológica, que elabora tipologías desde la generalización de características e igualando el tipo mujer y el tipo varón, al ser, ser mujer o esencia femenina, ser varón o esencia masculina. Sobre estas asimilaciones se cierne acertadamente la crítica de Badinter aunque su reprensión, tal y como hemos recogido en el apartado segundo de este artículo, no va más allá de una visión sociológica y por tanto no suficientemente profunda, cuando dice que cada

41 "Si el hombre pretende disponer de su propio disponer, entonces hace mal uso de su libertad, por decirlo rápidamente. $\mathrm{Y}$ ahí es donde está la tragedia humana. El drama humano estriba en esa equivocación, esa equivocación ha tenido lugar, queremos disponer de nuestro disponer, pero eso contraría nuestro carácter creatural, es decir, la misma distinción real de esencia y acto de ser". Ibidem, 129.

42 "Sostengo, en cambio, que lo que es idéntico es Dios, y lo que no es idéntico como Dios no es idéntico; no hay identidad relativa, parcial, sino que lo que no es idéntico es distinto realmente. La distinción real descubierta por Tomás de Aquino la tomo muy en serio, y después de ella hablar de identidad relativa queda excluido: el único ser idéntico es Dios. La identidad de Dios permite la tripersonalidad. La distinción real es aquella que no permite que una criatura personal espiritual tenga réplica en sí misma, no es trinitaria, sino unipersonal”. Ibidem, 194.

${ }^{43}$ Un ejemplo, Ética, op. cit., 51, 62, 73.

${ }^{44}$ Ibidem, 109-116.

45 Polo explica la teoría de los tipos ideales de Weber de gran uso en la Sociología moderna. Para una explicación más pormenorizada de este tema cfr. A. RODRÍGUEZ SEDANO, "Tipos sociales y personas singulares: 'familias' y familia”, en A. BERNAL (Ed.), La familia como ámbito educativo, $2^{\mathrm{a}}$ ed., Rialp, Madrid, 2009, 89-112. 
mujer es lo que es, no tanto por ser mujer, como por pertenecer a una clase social, a una cultura, por tener alguna capacidad individual específica, etc.

La distinción de tipo "antropológico" del tipo "sociológico" que realiza Leonardo Polo sirve para discernir que no se puede reducir lo que es ser mujer, ser humano, ser persona, ser sujeto de derecho a un tipo "sociológico". Y lo mismo se puede afirmar de ser varón. En este sentido es clarificadora la siguiente explicación:

"Sin embargo, la consideración sociológica de los tipos no agota la noción de tipo porque, en definitiva, ésta es de cada uno. De modo que si tomamos los tipos de manera sociológica podemos hacer una generalización de los caracteres, con lo cual se pierde lo que es típico de cada uno, porque ya saben que las generalizaciones pierden contenido. En efecto, la extensión va en contra de la riqueza de contenido; cuanto más general es una noción, más indeterminada es. Un tipo humano entendido en términos sociológicos es útil para hacer sociología, pero no tiene en cuenta el carácter singular de tipo. Cada uno es un tipo, y en lo típico de cada uno hay una distinción. De manera que no hay dos hombres iguales; pueden ser parecidos pero no iguales" ${ }^{\prime 4}$.

El tipo es una modalización de la especie, la especie humana está tipificada. Sociológicamente una modalización se adquiere generalizando, haciendo grupos de individuos con características comunes, que son tipos ideales, "nocionales". De la misma manera se procede desde la psicología, generalizando rasgos psicológicos se hacen grupos de tipos. Sin embargo, estas ciencias no pueden estudiar todos los rasgos típicos de cada ser humano, porque éstos son rasgos de lo concreto en cada uno ${ }^{47}$. Antropológicamente, la modalización tiene más contenido, recoge más caracteres diferenciales, capturando lo propio de cada individuo, lo real, los tipos reales, cada ser humano. La tipificación es la modalidad de la especie en cada ser humano. Esto está en el nivel de la naturaleza, dentro de la esencia. "Los hombres se distinguen por sus rasgos típicos, que también tienen que ver con las dimensiones no corpóreas; en el hombre está tipificada su inteligencia y está tipificada su voluntad humana"\$8.

\footnotetext{
${ }^{46}$ La esencia del hombre, op. cit., 109. "La sociología entiende las distinciones tipológicas aislándolas de su completitud esencial, es decir, como nociones generales", Antropología I, op. cit., 183.

47 La esencia del hombre, op. cit., 112.

48 Ibidem, 118.
} 
Cada hombre realiza un tipo, aunque esto es inferior a la esencia: "lo más estrictamente típico en el hombre es que es justamente cada uno" ${ }^{49}$. Es en la esencia, en lo que más se llega a diferenciar a un ser humano de otro aunque las diferencias arrancan de la naturaleza. Pero la realidad de los tipos humanos también sirve para explicar la igualdad entre personas. En la argumentación sobre los tipos humanos e inspirándose en Santo Tomás, Polo razona sobre el fundamento de la igualdad entre seres humanos: "los tipos son algo así como un reparto de la especie, de manera que el contenido de los tipos en vez de ser un motivo para decir que hay seres humanos superiores e inferiores, la tipificación de los seres humanos establece una igualdad en los individuos" ${ }^{50}$. Los seres humanos no son iguales en el sentido de ser exactamente iguales, las características de la especie se reparten, presentan matices en cada ser humano, y en la comparación de las matizaciones, unas son mejores en unos individuos que en otros, y éstos materializan propiedades en los que destacan más. En la igualdad de ser cada persona un típico humano nos debemos respeto y honor.

Conforme a esta argumentación, ¿qué son los tipos varón y mujer? ¿Tipos sociológicos? ¿Tipos antropológicos? ¿Matizan la especie de manera similar las mujeres? ¿Y los valores? ¿Podríamos considerar una esencia femenina y una esencia masculina? ¿Es posible mantener una relación de igualdad a la vez que se respeta la diferencia? Leonardo Polo se refiere a las mujeres y varones como tipos básicos. Estas categorías responden a la elaboración de una tipología sociológica pero también con fundamento antropológico ya que es la primera distinción típica de la humanidad. Mujer y varón tienen esencia humana pero desde la perspectiva de la especie son distintos tipos, varón y mujer, lo humano se realiza de distinta manera. "Eso quiere decir que lo femenino y lo masculino no están vinculados -por decirlo así- por lo generativo" ${ }_{51}$. La tipología humana no es de índole corpórea, sino que es anímica, en el orden natural, sustancial y sobre todo en el esencial ${ }^{52}$. La diferencia entre mujeres y varones no sólo es en lo sexual sino que se aprecia en otras dimensiones como la psicológica. "Se puede decir que hay dos tipos de seres humanos: el hombre y la mujer, porque la diferencia sexual es mucho más acentuada en

\footnotetext{
49 Ibidem, 72.

50 Ibidem, 112. La misma idea se repite en Ética, op. cit., 72.

51 La esencia del hombre, op. cit., 110.

52 Ibidem, 113.
} 
nuestra especie que en las otras, pues tiene connotaciones espirituales" ${ }^{93}$. De lo que se deduce, y así lo expone Polo directamente que ser mujer no se define por el hecho de tener hijos ${ }^{54}$. Con esta explicación se puede entender que la maternidad no es lo único que define qué es la mujer.

Si lo que se esencializa es cada tipo, y la esencia es la perfección de la naturaleza, y la naturaleza está tipificada, la esencialización también lo está, y por tanto se podría hablar de esencia humana femenina y de esencia humana masculina. Esta argumentación en abstracto sigue una lógica sólidamente elaborada pero no encontramos en la Antropología de Polo un estudio de las diferencias que constituyen la esencia de cada sexo. Únicamente un breve apunte consuela ante la dificultad de capturar las características diversas de la esencia masculina y de la femenina: "como la naturaleza está tipificada evidentemente la 'esencialización' también lo está; aunque en seguida hay que añadir otra cosa, y es que en lo esencial los hombres se parecen más que en el nivel de los tipos" ${ }^{\prime 5}$. Una tarea que se deduce de esta observación es que se podrían diferenciar virtudes femeninas y virtudes masculinas aunque también cabe mirar a las virtudes humanas en dos manifestaciones, masculina y femenina, según los tipos $^{56}$.

La distinción entre varón y mujer como expresión de una tipología sociológica es producto de una generalización y por tanto se pierde contenido para comprender a cada varón y a cada mujer: "Las mujeres no son todas ellas un tipo homogéneo. Se puede decir: generalizo ese género para distinguirlo de otro tipo, pero eso es un tipo generalizado. Por lo tanto, no hay tipos reales completos, el tipo real completo es cada mujer y cada varón" ${ }^{\text {57 }}$.

${ }^{53}$ Ética, op. cit., 72.

54 "La mujer no existe solamente para continuar la especie, para tener hijos; si se casa, evidentemente que sí, pues el fin del matrimonio son los hijos, pero eso no agota la diferencia entre varón y mujer, que no es meramente sexual, sino que es una diferencia típica y afecta a lo natural, a lo psíquico, etc., pues una mujer es diferente de un hombre". Ibidem, 110.

55 La esencia bumana, op. cit., 112. La esencia humana, en cada tipo humano, es completa. Es completa la esencia femenina y también la masculina. Constituyen una dualidad por encima de la dualidad corpórea.

56 Sirve de ejemplo la propuesta de Ahedo, que expone cómo las virtudes se manifiestan de modo diverso entre la mujer y el varón partiendo de la Antropología de Polo. Cfr. J. AHEDO RUIZ, La dualidad tipológica básica desde la Antropología trascendental de Polo. Cómo la sindéresis clásica resuelve un problema moderno, tesis doctoral, Universidad de Navarra, Pamplona, 2009, 333-377. Disponible en http://hdl.handle.net/10171/27845.

${ }^{57}$ La esencia humana, op. cit., 111. "Cada mujer es cada mujer, y no sólo esencialmente, ni personalmente, sino típicamente; e igual sucede en el varón”. 
En la conformación de los tipos humanos media la cultura. Por los rasgos culturales se tipifica de un modo cada persona haciendo agrupaciones entre ellas a veces muy marcadas, distinguiéndolas o asemejándolas entre sí por unos rasgos generales, esta gran distinción o gran asimilación afecta también a los tipos básicos de varón y mujer ${ }^{58}$. Con la cultura se interpreta la realidad, también de los tipos humanos, se da sentido y valor, el lenguaje, los modos de expresión corporal, los roles, las funciones. La reivindicación contemporánea de la libertad que se plasma en una reinterpretación cultural de la identidad es razonable, y es que las personas toman conciencia de que no son sólo el resultado de una generalización aunque se manifiesten típicamente ${ }^{59}$. Sin embargo, la cultura es necesaria, el ser personal no se reduce a un tipo cultural, pero presenta una tipificación cultural en la esencia.

Ser varón, ser mujer es algo típico del ser humano, algo dado y algo trabajado, elaborado, construido, que puede crecer, que se educa, dinámico:

"Mientras que el tipo puede describirse como el natural de cada uno, su temple, su temperamento, el cariz de sus modos de disponer, la esencia es la finalización de el natural desde la persona y en atención a ella, es decir, la organización que hace coherentes los rasgos del tipo" ${ }^{00}$.

\section{FAMILIA: MATERNIDAD, PATERNIDAD Y FILIACIÓN}

No disponemos de un estudio específico de Polo sobre la familia pero sí podemos obtener en sus diferentes obras algunas reflexiones sobre la familia, la maternidad, la paternidad, la filiación y la educación en la familia. Lo novedoso de su aportación sobre este tema, no son tanto las ideas acerca de la familia, aunque algunas consideraciones sí que se elaboran con un enfoque sin-

${ }^{58}$ Ética, op. cit., 72.

59 "La manifestación del ser personal es modulada, ante todo, por los tipos. La correspondencia entre los tipos y la cultura permite ciertas generalizaciones, que son propias del método de la sociología cultural. Sin embargo, no conviene olvidar que el tipo pertenece a cada persona, por lo que la generalización de los tipos sólo permite una clasificación somera de los seres humanos: hablando con rigor, los tipos son de las personas, y no al revés (encerrar a las personas en tipos". Ética, op. cit., 75 .

${ }^{60} \mathrm{Y}$ por tanto, el ser humano se hace: "la conquista creciente de la dependencia de lo humano respecto del ser persona. Dicho depender es estrictamente la esencia del hombre; pero no es estático, sino que es menester conquistarlo, porque la esencia del hombre sólo es en 'tanto que crece' (si no creciera, no dependería de la persona, y si ese crecimiento no fuera libre, no pasaría de ser el de un organismo corpóreo)". Ibidem, 75. 
gular, sino cómo están fundamentadas en la Antropología que desarrolla ${ }^{61}$. Hemos extraído esas ideas agrupándolas en continuidad con el hilo de la argumentación expuesta en los apartados anteriores con el siguiente orden: primero consideramos qué es la sociedad, segundo qué es la familia, y terminamos con una aproximación a las relaciones intersubjetivas familiares.

Desde la concepción de sociedad que argumenta Polo, se comprende que urge solucionar como restaurar la relación varón y mujer para lograr una adecuada convivencia en la sociedad. Los seres humanos necesitan unos de otros, necesitan convivir y coordinarse porque son tipos diversos. Los tipos tienen que respetarse, que descubrirse: "hay que reconocer que el otro no es exactamente como yo" ${ }^{2}$. El respeto indica el requerimiento de la Ética. La organización social que precisa el hombre es superior a la mera convivencia para la subsistencia. La sociabilidad se fundamenta en la realidad de los tipos, y la esencialización, desde la persona, es en sociedad; el fin de la sociedad es la esencialización, y las virtudes que "materializan" esta esencialización tienen un carácter social. Vivir en sociedad sólo es posible de un modo ético, con virtudes, y éstas no se adquieren sin sociedad. Los seres humanos por su ser personal y no estando finalizados por la especie, son superiores a ella, configuran la sociedad, enfocan sus relaciones, buscan unos fines. A esta relacionabilidad entre personas, Polo la denomina intersubjetividad. La manifestación en la sociedad de esta propiedad es el establecimiento de la institución social.

"La única sociedad en sentido estricto es la humana: sociedad significa metaespecificación: relación entre seres vivos subjetivamente inteligentes. Dicho de otra manera: el hombre es un ser social porque es un ser dialógico, es decir, capaz de expresar lo que piensa a los demás y establecer así una red comunicativa. La sociedad, en última instancia, es la manifestación de lo interior a los demás en régimen de reciprocidad"63.

El ámbito social primario es la familia, y es sociedad primera porque se hace por la convivencia de los tipos básicos humanos, la mujer y el varón, quienes generan a otros seres humanos, miembros potenciales de otras sociedades. La educación en la familia enseña cómo son las relaciones varón y mujer, la re-

${ }^{61}$ Por ejemplo, es ilustrativa la argumentación de cómo la familia es una institución, es de orden ontológico y cómo surge con el hombre y el hombre con la familia. Cfr. Quien es el hombre, op. cit., 31,35 y 43 .

${ }^{62}$ La esencia del hombre, op. cit., 112.

${ }^{63}$ Ética, op. cit., 61. 
lacionabilidad de los tipos básicos; puede ser ésta, la enseñanza fundante de respeto y coordinación de los tipos humanos para la convivencia. Se aprende una doble lección en la familia, instrucción crucial para promover el desarrollo de la sociedad: el respeto a las mujeres y a los varones como muestra de la diversidad humana y la razón de este respeto, cada mujer y cada varón constituyen un tipo humano único. El respeto a la diversidad básica en la humanidad se transfiere como respeto a cada ser humano. La familia es la sociedad primaria, la institución básica que muestra que la humanización no se reduce a la hominización ${ }^{64}$. Polo hace una mención explícita de cómo en la familia se posibilita el reconocimiento de la mujer y del varón como personas ${ }^{65}$.

Los hombres nacen en una primera institución social que es la familia ${ }^{66}$; el hombre es naturalmente familiar y sin la familia no son posibles las tipificaciones humanas, ni las formas sociales suprafamiliares, la familia es célula social $^{67}$; las relaciones familiares, entre personas, son dialógicas, marido-mujer, padres-hijos: eso es lo primero que el hombre es. Y lo es en tanto que animal racional, en tanto que no está finalizado por la especie. Evidentemente, la generación sirve a la especie, pero no se agota en ello, sino que está presidida por relaciones solamente posibles si el hombre es un ser dotado de inteligencia y voluntad, capaz de amor constante ${ }^{68}$.

Por lo tanto, el ámbito natural de esencialización es la sociedad primaria, la familia, y para la esencialización es imprescindible la ayuda de otros. Para justificar la necesidad de la familia recurre a un común argumento antropológico: el hijo humano nace prematuramente, necesita crecer, alcanzar la madurez sapiencial-práctica y requiere la ayuda de los demás para crecer; no se puede aprender sin la relación social. "[...] la función primordial de la sociedad es la acogida, la educación de las nuevas generaciones" ${ }^{\$ 9}$. Sin embargo, la referencia que Polo hace a la educación familiar es situando lo que considera su primer objetivo, la integración afectiva ${ }^{70}$. La referencia a este fin educativo se comprende por el carácter de la vinculación familiar basada en un orden ético, el amor. Esta

\footnotetext{
64 Ibidem, 63.

65 "La familia es el reconocimiento de que la mujer es persona: y también, por parte de la mujer, de que el varón lo es". Ibidem, 80.

66 La primera forma de organización social es la familia, Ayudar a crecer, op. cit., 44.

67 Quien es el hombre, op. cit., 31.

68 Ética, op. cit., 62.

69 Antropología de la acción directiva, op. cit., 127.

70 Ibidem, 128.
} 
integración afectiva posible por el amor y cuidado del padre y de la madre es la base para desarrollar las capacidades del hijo en orden a la sociedad.

Polo sitúa en el mismo nivel de importancia para el buen desarrollo de los hijos a la madre y al padre. Se deduce que entiende la maternidad y la paternidad como un modo específico de relación interpersonal que se origina y mantiene en las distintas dimensiones del ser humano. Paternidad y maternidad no son sólo una relación de orden genético sino que se compone del orden del amor; la paternidad y maternidad se resuelven como una relación constituida en el vínculo entre padre y madre, prolongado en el hijo, y que sostiene el cuidado del mismo ${ }^{71}$. Respecto al hijo, la maternidad es tan importante como la paternidad; en la visión de ambos, Polo asocia a la madre modos concretos de su cuidado y educación del hijo, y al padre otros contenidos educativos pero sin conceder a uno más importancia que al otro. Por el contrario, lo que advierte como preocupante es la falta de cuidado del padre o de la madre, o la falta de armonía en los cuidados de madre y padre. Ese cuidado, ese amor es la base de la confianza del hijo en ellos y en sí mismo ${ }^{72}$.

"Esa comunidad, esa participación de los dos en la constitución de la dotación genética y, por tanto, del crecimiento de la bio-génesis, de la generación del hombre, expresa el carácter unitivo que existe entre el amor de los padres y el amor a los hijos. El amor de los esposos entre sí y el amor de los esposos al hijo no son muy separables, porque los padres reconocen su mutuo y propio amor en el bijo; el hijo es obra común. El hijo es tanto del padre como de la madre; lo es unitariamente"

La maternidad, la paternidad y la filiación son las relaciones entre personas que establecen unos vínculos permanentes de valor trascendente. Este valor transcendente implica que:

a) las personas pueden conocer y reconocer los vínculos que se realizan entre ellos; el acto procreativo, el núcleo de la paternidad y de la maternidad, sobrepasa la unión sexual de una mujer y de un varón ${ }^{74}$. La vida humana no

${ }^{71}$ Ibidem, 127.

${ }^{72}$ Ibidem, 128.

${ }^{73}$ Ayudar a crecer, op. cit., 78.

${ }^{74}$ Ibidem, 129. La misma idea en Ética, op. cit., 62. "El alma humana espiritual no procede de los padres es creada por Dios", Aprender a querer, op. cit., 36. "Por ser la inteligencia propia de cada ser humano, no se transmite genéticamente; el origen de la inteligencia es divino. Ahora bien, por ser el hombre un animal, es generado", Ética, op. cit., 52. 
sólo es de carácter físico, la generación humana procede de los padres pero el carácter personal del hijo no procede de ellos; los padres lo son por el hijo pero ni ellos ni el hijo son personas por generación ${ }^{75}$. La vida que viene de los padres es recibida por el hijo, y es reforzada por la persona del hijo, es expresada por él. Esa manifestación o expresión es la esencialización ${ }^{76}$. Padre y madre se hacen respectivos respecto al hijo. Y el hijo adquiere conciencia de su origen $^{77}$. La paternidad y maternidad confirman la importancia del matrimonio porque generan a una persona nueva. "[...] los padres se subordinan al bijo, puesto que están finalizados por el hijo en cuanto persona, y no sólo finalizados por la procreación de la especie [...]" ${ }^{\prime 78}$. Pero no se puede afirmar con propiedad que una mujer se autorrealiza con la maternidad, el hijo no es el efecto de su autoperfección aunque siendo madre, la mujer se perfecciona. Lo mismo se puede sostener respecto al varón.

b) Al configurarse a partir de una relación biológica otra que la trasciende, de personas que tienen inteligencia, alma, los vínculos entre ellas tienen también una dimensión ética. $\mathrm{Y}$ esta aseveración implica entender que la familia sea una institución. La relación del padre y la madre con su hijo es un tipo de reproducción transido de sentido ético. La generación de un ser humano tiene una dimensión biológica inmediatamente trascendida: tanto los padres como el hijo son seres inteligentes. Las relaciones integrantes de la institución familiar son posibles por ello ${ }^{79}$.

c) El hombre es radicalmente hijo ${ }^{80}$. Los seres humanos con su conciencia de hijos admiten que dependen de alguien, y padres y madres advierten que alguien depende de ellos. La renuncia a ser hijo trae consigo el Individualismo y éste es un déficit antropológico ${ }^{81}$. El ser humano no es individuo es per-

75 Antropología trascendental, II, op. cit., 15.

76 Ibidem, 16.

77 Antropología de la acción directiva, op. cit., 129. Polo habla de paternidad pero no sólo refiriéndose al varón, sino también a la madre. En este escrito preferimos nombrar tanto al padre como a la madre porque puede conducir a equívocos hablar de la paternidad como representación de ambas realidades, la de la madre y la del padre.

78 Ayudar a crecer, op. cit., 77.

9 Etica, op. cit., 52.

Ayudar a crecer, op. cit., 36.

81 Etica, op. cit., 62. "A su vez, la relación del hijo con el padre, por ser constitutiva y originaria, remite inevitablemente al origen del propio ser: el hombre es interpelado por su propio origen. Así se evita la caída en el narcisismo - tan extendido en la sociedad actual-, que viene a ser la exclusión de la conciencia del origen. Por ello, tanto la paternidad como la filiación son relaciones permanentes. Ningún hombre está autorizado a entenderse como ex-padre, como tampoco 
sona y por ello las relaciones con los demás van más allá del intercambio de medios, son más que interacciones, suponen crecimiento.

\section{RESPUESTAS FINALES}

A modo de conclusión incoamos las respuestas a las cuestiones que subrayamos en este artículo:

a) ¿La naturaleza marca un destino específico a la mujer? ¿Es la maternidad algo instintivo? La respuesta es negativa. Varón y mujer son personas que disponen al modo de su esencia libremente desde su ser personal. Este planteamiento, considerar la maternidad como destino único en el que la feminidad llega a su plenitud, responde a una visión naturalista y reductiva de la naturaleza humana y de la persona. La naturaleza humana no es una naturaleza más del cosmos y su fin no viene del mismo, la persona no es únicamente un individuo de una especie.

b) ¿Se puede definir la naturaleza femenina o la esencia de la feminidad? Se pueden definir y distinguir, igual que en los varones, aunque es difícil concretar lo específico de cada sexo, sobre todo a partir de la esencia. En cuanto se pretende un estudio más fenomenológico y se hacen generalizaciones de la feminidad y de la masculinidad, nos perdemos en delimitar lo esencial de cada individuo en relación con la condición sexuada. En la esencia humana se manifiesta crecimiento mediando lo cultural; cada ser humano como tipo es único, y presenta diferencias y particularidades en el nivel de la naturaleza, de la esencia y de la persona. Las diferencias básicas de las mujeres respecto a los varones se manifiestan más pronunciadas en la naturaleza, a partir de la cual, se dota de esencia cada persona, y en ese proceso de autoperfección, se suman más diferencias que las naturales -las comunes entre personas del mismo sexo y las propias de cada persona- que proceden de la cultura y la educación. Es claro que el disponer se puede manifestar de modos muy diversos según la persona de la que depende el disponer y de los disponible, lo que explica la diversidad de "presentaciones" de la esencia femenina y la variabilidad que puede acaecer a lo largo de la historia, precisamente por la libertad y por el cambio de condiciones vitales que da lugar a la necesidad de diversas coordinaciones

nadie puede comprenderse a sí mismo como ex-hijo. Por ser esta relación constitutivamente originaria, posee una vigencia extratemporal”. 
de los tipos. La esencia femenina se manifiesta en la maternidad pero ésta no es el único modo en que la mujer crece ni como mujer ni como persona.

c) ¿Qué relación hay entre naturaleza, cultura, libertad e identidad personal? La cultura es un resultado y uno de los aspectos de la esencialización, del disponer -la esencia- del tener, desde la perspectiva del ser personal. La libertad es en el disponer y es en la persona. Propiamente habría que hablar de ser personal y no de identidad; la noción de identidad desde una perspectiva filosófica conduce a presentar a un ser humano perdido en generalidades, en las identificaciones que elabora y dotado de una libertad que no es real. Lo radical en el ser humano es ser persona y a partir de esta idea adquiere valor por elevación ontológica, la naturaleza y la cultura humanas. Así que la mujer, es radicalmente persona y la libertad es una propiedad transcendental; la naturaleza y la cultura, desde el ser personal, es algo que la mujer tiene y pertenece a un orden ontológico inferior al del ser personal. Propiamente a la mujer no hay que hacerla, no es un resultado ni natural ni cultural.

d) ¿Se construye la identidad de las personas por el desempeño de unos roles o funciones? La identidad no se construye, el ser personal es recibido, lo cual se manifiesta en la condición común de todos los seres humanos de ser hijos. Somos hijos gracias a un padre y a una madre pero no sólo gracias a ellos, porque somos más que lo que lo que los padres aportan para generarnos. Esta realidad permite reconocer el valor de la paternidad y la maternidad que se expresa en la aceptación libre de tener y cuidar a sus hijos, sabiendo que éstos no son un producto de su obrar, porque cada persona es más ser que lo que han aportado sus padres. Y ambos, padre y madre manifiestan su ser personal en las relaciones interpersonales que constituyen la familia. La paternidad, la maternidad y la filiación son relaciones específicas interpersonales constituidas por unos vínculos que se manifiestan en unas funciones de cuidado y que significan que las personas dependen de otros para vivir y que su origen no es de este mundo. Las personas no son el producto de sus padres, ni son su autoproducto, y por lo tanto no es razonable afirmar que son el resultado de las funciones que cumplen.

e) ¿El planteamiento moderno de autorrealización como medio de construir la identidad coincide con el proyecto de crecimiento personal? No coinciden y podemos esbozar dos razones para justificar esta respuesta. Una ya está dada en la cuestión precedente, los seres humanos no construyen su identidad aunque sí finalizan su naturaleza; esta finalización es un proceso de autoperfección, un disponer de lo disponible, no un disponer del disponer que se puede comprender también como un proyecto de crecimiento de la persona. 